\title{
Antioxidant and Cytotoxicity Potential of Six Synthesized Chalcones
}

\author{
S. L. Kouakou ${ }^{*}$, M. Ouattara ${ }^{2}$, J. P. N'Guessan², S. Coulibaly², A. G. Irié-N'Guessan1, \\ G. Kouakou-Siransy ${ }^{1}$ \\ ${ }^{1}$ Laboratoire de Pharmacologie, UFR Sciences Pharmaceutiques, Université FHB, Abidjan, Côte d'Ivoire \\ ${ }^{2}$ Département Chimie Thérapeutique et de Chimie Organique, UFR Sciences Pharmaceutiques, Université FHB, Abidjan, \\ Côte d'Ivoire \\ Email: *giselekouakou@yahoo.fr
}

How to cite this paper: Kouakou, S.L., Ouattara, M., N'Guessan, J.P., Coulibaly, S., Irié-N'Guessan, A.G. and Kouakou-Siransy, G. (2018) Antioxidant and Cytotoxicity Potential of Six Synthesized Chalcones. Pharmacology \& Pharmacy, 9, 536-546. https://doi.org/10.4236/pp.2018.912042

Received: November 1, 2018

Accepted: December 23, 2018

Published: December 26, 2018

Copyright (C) 2018 by authors and Scientific Research Publishing Inc. This work is licensed under the Creative Commons Attribution International License (CC BY 4.0).

http://creativecommons.org/licenses/by/4.0/

\begin{abstract}
Background: Chalcones are open-chain flavonoids which display a large number of pharmacological activities such as cytotoxic, anti-inflammatory including antioxidant. The objective of this study was to assess antioxidant and cytotoxic activity of six synthesized chalcones. Methodology: For the current experiments, 1,3-diphenylpropenone (compound R) was used as molecular model to synthetize six compounds, namely three

benzyl-benzimidazolyl-chalcones (U1, U2, WAC1) and three imidazopyridinyl-chalcones (V1, V2, V3). All the compounds were evaluated for their ability to scavenge the stable free $\mathrm{ABTS}^{++}$radical cation, according to the method develop by Choong et al. In addition, the cytotoxicity test described by Price et al., was performed using healthy human cell line, then in human malignant cell lines (HEP-2, A549). Results: All synthesized chalcones reduced the $\mathrm{ABTS}^{\circ+}$ radical cation. Indeed, benzyl benzimidazolyl compounds WAC1, U1, U2, by developing respectively $39.61 \%, 66.09 \%$, and $84.20 \%$ percentages of reduction, showed an antioxidant effect 6,11 and 14 times greater than the compound $\mathrm{R}(6.14 \%)$. As a result, imidazopyridinyl-chalcones compounds, namely V1, V2 and V3 reduced the $\mathrm{ABTS}^{\circ+}$ radical cation at $91.62 \%, 99.84 \%$ and $97.45 \%$ respectively, being 15 and 16 times more active than the compound R. About cytotoxicity, V2 inhibited not significantly HEP-2 malignant cells growth at $48.64 \%$, compared to the standard product, i.e. doxorubicin that inhibited the growth of the same cells at $42.37 \%$. WAC1 inhibited significantly the growth of A549 malignant cells at $89.53 \%$, more than doxorubicin which percentage of growth inhibition was $71.58 \%$. Conclusion: The presence of the $\alpha, \beta$-unsaturated carbonyl system (or 1,3-diphenylpropenone) along with a benzimidazole or imidazopyridine heterocyclic ring is likely to contribute to both cytotoxic and antioxidant activities of these compounds.
\end{abstract}




\section{Keywords}

Chalcones, Antioxidant, Cytotoxic, HEP-2, A549, ABTS

\section{Introduction}

Chalcones are widely present in nature as important intermediates in the flavonoid biosynthetic pathway in various ferns and plant species [1]. The basic structure of chalcones contains a C6-C3-C6 backbone including two aromatic rings linked by an $\alpha, \beta$-unsaturated carbonyl group [1].

Numerous studies have described chalcones as compounds that have various pharmacological activities such as anticancer [2] [3], anti-inflammatories [4] [5], including antioxidants [6] [7].

Prompted by all these considerations, in an effort to design a unique template endowed both with radical scavenger properties and cytotoxicity activities, we replaced a phenyl ring of chalcone with heterocyclic rings namely imidazopyridine and benzimidazole. The purpose of the herein study was to evaluate the antioxidant and cytotoxic activity of six synthesized chalcones in the perspective to propose them as forward models on which we can rely for the development of new molecules effective against cancers.

\section{Materials and Methods}

\subsection{Chemicals}

Sodium chloride (Pharmivoire, Ivory Coast); Dimethyl sulfoxide (DMSO, Sharlau, Germany); ABTS and Trolox (Sigma-Aldrich, France).

\subsection{Samples under Study}

The six compounds tested, i.e. benzimidazolyl-chalcones (V1, V2, WAC1), and imidazopyridinyl-chalcones (V1, V2, V3), including molecular model (compound R), were synthesized and provided as pure powder by the Department of Organic and Therapeutic Chemistry of Training and Research Unit of Pharmaceutical and Biological Sciences (Côte d'Ivoire). From the molecular model (1,3-diphenylpropenone or compound R: Figure 1), chemical modifications were made on the aryl groups (ring A and B) to obtain the compounds under study.

The ring A replaced by benzimidazole or imidazopyridine rings, different substituted in ring B with electro donor element, allowed the synthesis of benzimidazolyl-chalcone derivatives (U1, U2, WAC1) and imidazopyridinyl-chalcones (V1, V2, V3). All of the chalcone hybrids were characterized by nuclear magnetic resonance $(300 \mathrm{MHz}$ for $1 \mathrm{H}$ and $75 \mathrm{MHz}$ for 13C) on a Brucker Avance 300. Mass spectra were recorded on a JEOL JMS DX300 spectrometer on mode ESI, and details on their synthesis and structural information are located in the supporting information [8] [9]. 


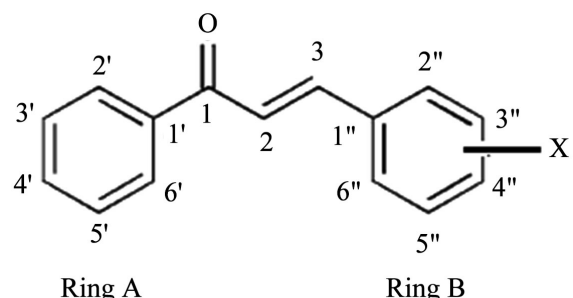

Figure 1. Molecular model (1,3-diphenylepropenone).

These products were in powder of different colors, insoluble in water and the usual organic solvents, except for dimethyl sulfoxide (DMSO).

\subsection{Antioxidant Ability Test}

We selected the decolourisation assay of $\mathrm{ABTS}^{*+}$ cationic radical for antioxidant potential evaluation, because it is suitable for the screening of hydrophilic as well as lipophilic molecules [10] [11].

\subsubsection{ABTS Test}

The test was performed according to Choong et al. [12]. ABTS [2,2'-azino-bis (3-ethylbenzothiazolin-6-sulfonic acid)] solution produces the $\mathrm{ABTS}^{++}$radical cation with a green blue colour in solution, for which the absorbance is measured at $730 \mathrm{~nm}$. Molecules that have an antioxidant ability, by donating an electron, reduce the $\mathrm{ABTS}^{+}$cation and turn the green blue reaction medium to a completely discoloured solution. The amount of antioxidant in the sample test is therefore inversely proportional to the formation of the ABTS.

\subsubsection{Obtention of Radical Cation ABTS ${ }^{\bullet+}$}

The $\mathrm{ABTS}^{\circ+}$ radical cation is obtained by mixing volume-by-volume $(1: 1 \mathrm{v} / \mathrm{v})$ of a stock solution ABTS $7.0 \mathrm{mM}$ with $2.6 \mathrm{mM}$ potassium persulfate solution, followed by incubation in the dark for 12 to 16 hours. The absorbance measured by spectrophotometry was adjusted between 1.0 and 1.5 at $734 \mathrm{~nm}$, adding $60 \mathrm{~mL}$ of phosphate buffer solution ( $\mathrm{pH}$ 7.4) to $1 \mathrm{~mL}$ of solution containing the radical $\mathrm{ABTS}^{+}$.

\subsubsection{Procedure of the ABTS Method}

The tests were carried out according to the following steps:

- Performing a sample concentration range ( $1-0.5-0.25-0.125-0.625)$, by successive dilutions to half $(1 / 2)$ in DMSO;

- Adding in a test tube, $100 \mu \mathrm{L}$ of the sample $+2500 \mu \mathrm{L}$ of ABTS reagent for each concentration, then incubate in the dark for 30 minutes;

- Preparing the negative control (white): Mix of $100 \mu \mathrm{L}$ of DMSO + $2500 \mu \mathrm{L}$ of ABTS reagent then incubation in the dark for 30 minutes;

- Preparing the positive control (Reference): standard of an antioxidant (Trolox) which absorbance was measured under the same conditions as the samples: mix $100 \mu \mathrm{L}$ of Trolox $+2500 \mu \mathrm{L}$ of ABTS reagent, then incubate in darkness for 30 minutes; 
- $\quad$ Reading the absorbance at $734 \mathrm{~nm}$ (UV-VIS spectrophotometer);

- Performing three (3) times reading for each compound.

The results, expressed as percentage of reducing the $\mathrm{ABTS}^{{ }^{+}}$radical cation, were calculated at the dose of $1 \mathrm{mg} / \mathrm{mL}$ for all the samples tested, including Trolox (standard substance), according to the following formula:

$$
\% \text { inhibition }=\frac{D O_{1}-D O_{2}}{D O_{1}} \times 100
$$

$D O_{1}$ : average Optical Density of neutral control;

$\mathrm{DO}_{2}$ : average Optical Density of tested compound.

\subsection{Cytotoxic Capacity}

It was carried out at Chatenay Malabry biology laboratory (Paris-France). The evaluation focused on a healthy umbilical endothelial cell line (HUVEC) and two (2) malignant lines of human origin, namely a liver cancer line (HEP-G2), and a lung cancer line (A549).

\subsubsection{Cell Culture and Cytotoxicity Tests}

HUVEC, HEP-G2, A549 cells were cultured in specific media supplemented with $10 \%$ Foetal Calf Serum (FCS) and 1\% Penicillin Streptomycin (PS). The autotoxicity test with MTT was carried out according to the method described by Price et al. [13].

\subsubsection{Obtention of Samples}

- A fresh solution at $10 \mathrm{mM}$ mixed with DMSO was prepared for each tested sample;

- Positive control: Doxorubicin (hydrochloride, $5 \mu \mathrm{M}$ );

- Negative control: DMSO at $0.1 \%$, and untreated control (endothelial cells alone, i.e. $100 \%$ viability).

\subsubsection{Procedure of the Cytotoxicity Tests}

The tests were carried out according to the following steps:

- Day 1: inoculating 3 wells with 5000 cells $+100 \mu \mathrm{L}$ of each sample then incubating them for 24 hours;

- Day 2: treating cultures with additional $100 \mu \mathrm{L}$ of the sample;

- Day 3: carrying out the MTT autotoxicity test after 48 hours of incubation and analysing in cytometry;

- Measuring the optical density (OD) 3 times for each sample and the controls. The results, expressed as percentage of inhibition cells growing, were calculated at using the same formula of antioxidant percentage inhibition.

\subsection{Statistical Method}

Data were analyzed using Graph Pad Prism ${ }^{\circledast} 7.0$ software. The Dunnett's test compared mean values $\pm \mathrm{SD}$ (standard deviation) by analysis of variance (ANOVA) at risk $\alpha=0.05$. 
The codification for statistically significant difference was: ${ }^{*}: 0.01<\mathrm{p} \leq 0.05$; ${ }^{* *}: 0.001 \leq \mathrm{p} \leq 0.01 ;{ }^{* *}: \mathrm{p}<0.001$.

\section{Results}

\subsection{Antioxidant Potential (Figure 2)}

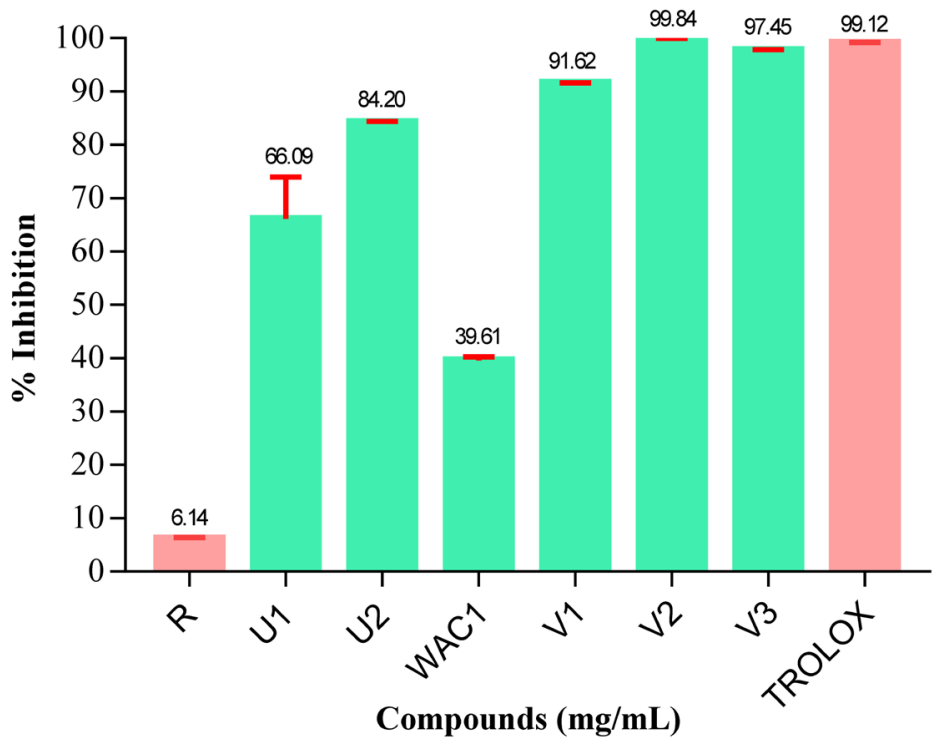

Figure 2. Compounds antioxidant potency. Dunnett's test at risk $\alpha=0.05 \%$. Values measured 3 times and expressed on average \pm SD (standard deviation). ${ }^{* *}: \mathrm{p} \leq 0.001$ : Significant difference compared to R: U1 $(p=0.0001)$, U2 $(p=0.0001)$, WAC1 ( $p=$ $0.0001)$, V1 $(\mathrm{p}=0.0001), \mathrm{V} 2(\mathrm{p}=0.0001), \mathrm{V} 3(\mathrm{p}=0.0001)$.

\subsection{Cytotoxicity Activity on Human Healthy Line (HUVEC) (Figure} 3)

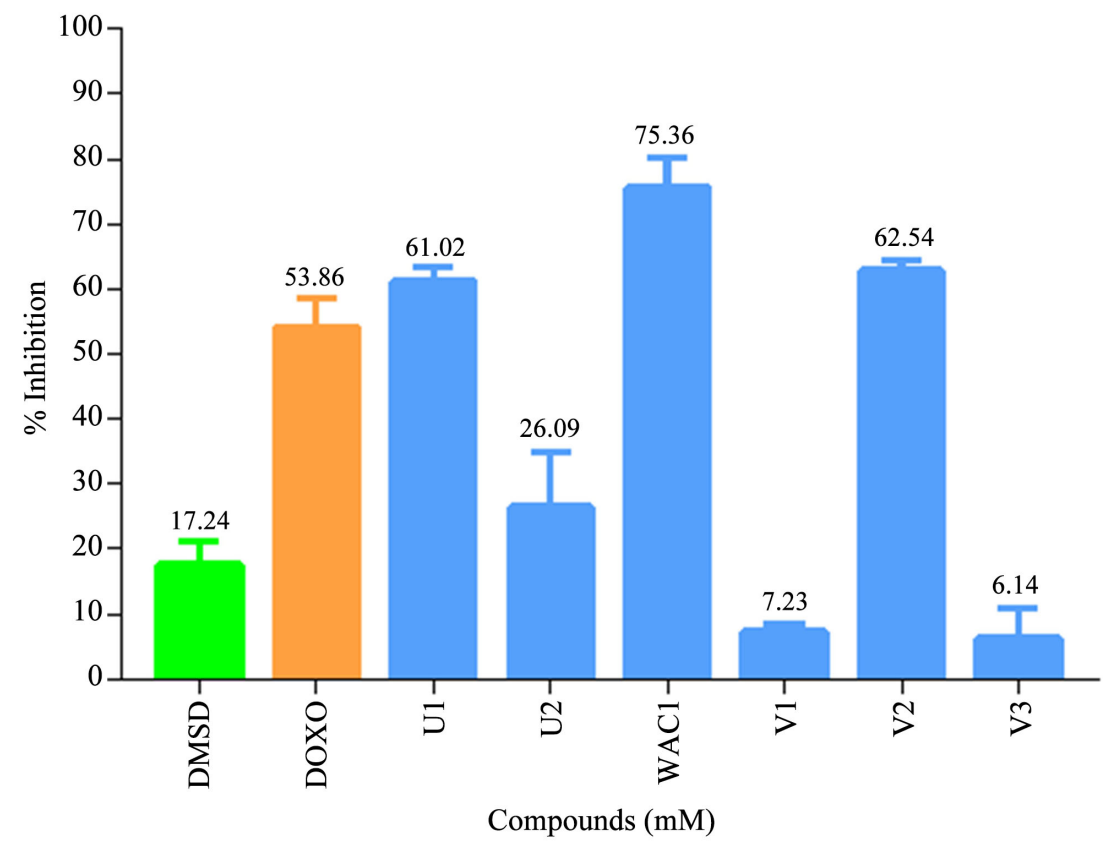

Figure 3. Cytotoxic effect of compounds against healthy human cells HUVEC. 


\subsection{Cytotoxicity Activity on Human Hepatic Malignant Line} (HEP-G2) (Figure 4)

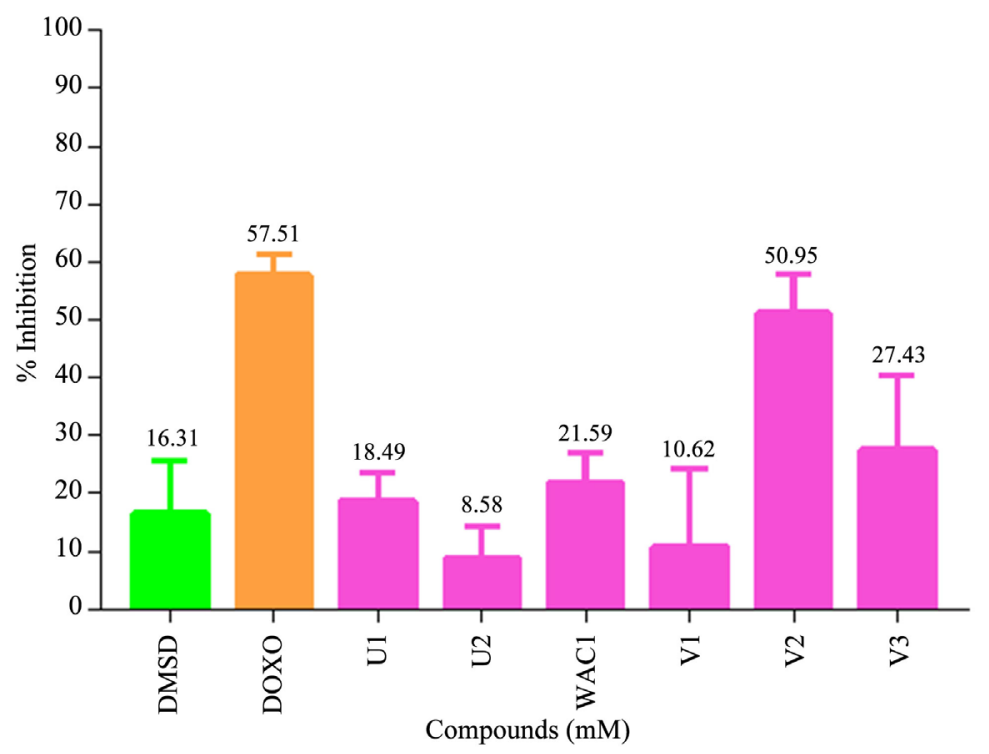

Figure 4. Cytotoxic effect of compounds against hepatic malignant cells HEP-G2.

\subsection{Cytotoxicity Activity on Human Pulmonary Malignant Line (A549) (Figure 5)}

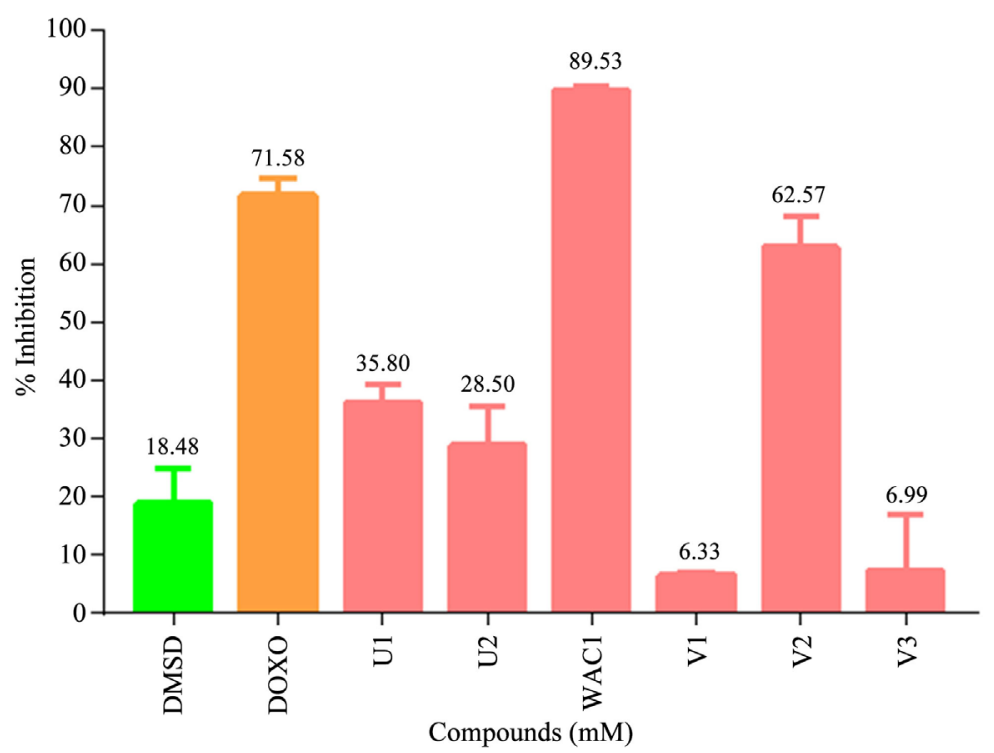

Figure 5. Cytotoxic effect of compounds against pulmonary malignant cells A549.

\section{Discussion}

Antioxidant screening showed that in benzimidazolyl-chalcones series, the introduction of a phenyl group on pyrrolic-N (U1), or a hydroxyl group substitution in position 2 (U2) of $N$-benzylbenzimidazolyl-chalcones, allowed these compounds scavenging the $\mathrm{ABTS}^{-+}$with a potent respectively 11 and 14 times greater than that of the molecular model. 
Our results are compatible with those reported by Murti et al. [14], who specified in their study that the antioxidant activity of benzimidazolyl-chalcones was around $39 \%$ to $70 \%$. Also, our results suggest that the presence of electron-donating substituents type hydroxyl on benzylbenzimidazolyl-chalcone (U2), is favorable for the enhancement of antioxidant potency, as revealed by the work of Prakash et al. [15]; Ghawalkar et al. [16]; and Lembege et al. [17].

In imidazopyridinyl-chalcones series, the introduction of hydroxyl group at position 2 or $3(\mathrm{~V} 1, \mathrm{~V} 2)$; or dimethylamine $\left[-\mathrm{N}\left(\mathrm{CH}_{3}\right)_{2}\right]$ at position 4 (V3), made possible to obtain compounds with high antioxidant potential respectively at $91.62 \%, 99.84 \%$ and $97.45 \%$, similar to that of the positive control (Trolox: $99.12 \%)$ and 15 to 16 times greater than that of the molecular model.

The cytotoxicity study revealed that compound V2 inhibited HEP-2 malignant cells growth with a cytotoxic effect similar to Doxorubicin, whereas compound WAC1 was more cytotoxic against A549 malignant cells with a greater effect compared to Doxorubicin. In contrast, V1 and V3 molecules were not cytotoxic on healthy HUVEC cells, in comparison with DMSO control.

The mechanism action suggested for V2, whose cytotoxic effect was similar to that of doxorubicin on HEP-G2, is that it interacts as DNA intercalating agents leading to cell death [18].

The same mechanism action could also be attributed to WAC1, but the fact that its effect was superior to that doxorubicin on A549 cells, would allow us, to expand its action as an agent that can interact on the signalling pathways of cell transduction. Indeed, WAC1, would behave as an agonist of tumor necrosis factor $\alpha(\mathrm{TNF} \alpha)$ which selectively binds to TNFR1 receptors, activates the transduction of signals mediated by the apoptotic pathways TRADD and FADD, resulting in the stimulation of caspases which cleaves multiple proteins responsible for cell death [19] [20].

Our results are consistent with a recent work led by Kamal et al. [21], who showed that derivatives of chalcones vectorized by various heterocyclic rings like imidazopyridine, imidazopyrimidine or benzimidazole, exhibited significant antiproliferative activity against the A549 human lung malignant line.

\section{Conclusions}

The imidazopyridinyl-chalcones and benzimidazolyl-chalcones could be good profiles of antioxidant activity. Depending on the position of the phenolic group in phenyl ring, the radical scavenging activity of the imidazopyridinyl-chalcones decreased in the following order: $3-\mathrm{OH}>4-\mathrm{N}\left(\mathrm{CH}_{3}\right)_{2}>2-\mathrm{OH}$. In the benzimidazolyl-chalcones series, the presence of a $2-\mathrm{OH}$ group on the phenyl group was favourable to antioxidant activities when another phenyl group was inserted on pyrrolic-N. However, insertion of a 5-chloro group in benzimidazole didn't enhance the activity of corresponding chalcone (WAC 1).

In addition, the best cytotoxic activity was provided by benzimidazolyl-chalcone bearing a halogen at the 5-position of the heterocycle (WAC1). The reported 
structure-activity observations can strongly contribute to designing and synthesizing chalcones endowed of ABTS radical scavenging or cytotoxic activities.

\section{Acknowledgements}

We express our sincere gratitude to Chatenay Malabry biology laboratory (Paris-France) for the study of in vitro cytotoxicity on HUVEC, HEP-2 and A549 human cell lines and to CEISAM Laboratory of the University of Nantes (for chemical reagents, MS and NMR spectroscopy).

\section{Corresponding Author's Institution}

Laboratoire de Pharmacologie, UFR Sciences, Pharmaceutiques, Université FHB, 01 BP V34, Abidjan, Côte d'Ivoire.

\section{Conflicts of Interest}

The authors declare no conflicts of interest regarding the publication of this paper.

\section{References}

[1] Grotewold, E. (2006) The Science of Flavonoids. Springer, New York, 274 p. https://doi.org/10.1007/978-0-387-28822-2

[2] Sashidhara, K.V., Kumar, A., Kumar, M., Sarkar, J. and Sinha, S. (2010) Synthesis and in Vitro Evaluation of Novel Coumarin-Chalcone Hybrids as Potential Anticancer Agents. Bioorganic \& Medicinal Chemistry Letters, 20, 7205-7211. https://doi.org/10.1016/j.bmcl.2010.10.116

[3] Singh, P., Raj, R., Kumar, V., Mahajan, M.P., Bedi, P.M.S., Kaur, T., et al. (2012) 1,2,3-Triazole Tethered $\beta$-Lactam-Chalcone Bifunctional Hybrids: Synthesis and Anticancer Evaluation. European Journal of Medicinal Chemistry, 47, 594-600. https://doi.org/10.1016/j.ejmech.2011.10.033

[4] Jin, F., Jin, X.Y., Jin, Y.L., Sohn, D.W., et al. (2007) Structural Requirements of 2',4',6'-Tris(Methoxymethoxy) Chalcone Derivatives for Anti-Inflammatory Activity: The Importance of a 2'-Hydroxy moiety. Archives of Pharmacal Research, 30, 1359-1367. https://doi.org/10.1007/BF02977357

[5] Okunrobo, L.O., Usifoh, C.O. and Uwaya J.O. (2006) Anti-Inflammatory and Gastroprotective Properties of Some Chalcones. Acta Poloniae Pharmaceutica, 63, 195-199.

[6] Srivastava, S., Sonkar, R., Mishra, S.K., Tiwari, A., et al. (2013) Antidyslipidemic and Antioxidant Effects of Novel Lupeol-Derived Chalcones. Lipids, 48, 1017-1027. https://doi.org/10.1007/s11745-013-3824-0

[7] Vogel, S., Ohmayer, S., Brunner, G. and Heilmann, J. (2008) Natural and Non-Natural Prenylated Chalcones: Synthesis, Cytotoxicity and Anti-Oxidative Activity. Bioorganic \& Medicinal Chemistry, 16, 4286-4293. https://doi.org/10.1016/j.bmc.2008.02.079

[8] Sissouma, D., Ouattara, M., Koné, M.W., Menan, H.E., Adjou, A. and Ouattara, L. (2011) Synthesis and in Vitro Nematicidal Activity of New Chalcones Vectorised by Imidazopyridine. African Journal of Pharmacy and Pharmacology, 5, 2086-2093. https://doi.org/10.5897/AJPP11.550

[9] Ouattara, M., Sissouma, D., Yavo, W. and Kone, M.W. (2015) Synthèse et criblage antiplasmodial de quelques benzimidazolyl-chalcones. International Journal of Bio- 
logical and Chemical Sciences, 9, 1697-1710. https://doi.org/10.4314/ijbcs.v9i3.48

[10] Awika, J.M., Rooney, L.W., Wu, X., Prior, R.L. and Cisneros-Zevallos, L. (2003) Screening Methods to Measure Antioxidant Activity of Sorghum (Sorghum bicolor) and Sorghum Products. Journal of Agricultural and Food Chemistry, 51, 6657-6662. https://doi.org/10.1021/jf034790i

[11] Osman, A.M., Wong, K.K.Y., Hill, S.J., et al. (2006) Isolation and the Characterization the Degradation Products of the Mediator ABTS-Derived Radicals Formed upon Reaction with Polyphenols. Biochemical and Biophysical Research Communications, 340, 597-603. https://doi.org/10.1016/j.bbrc.2005.12.051

[12] Choong, C., Van-Den, T.T. and Roger, F. (2007) Antioxidant Activities, Phenolic and Beta-Carotene Contents of Sweet Potato Genotypes with Varying Flesh Colours. Food Chemistry, 103, 829-838.

https://doi.org/10.1016/j.foodchem.2006.09.033

[13] Price, P. and Mc Millan, T.J. (1990) Use of the tetrazolium assay in measuring the response of human tumor cells to ionizing radiation. Cancer Research, 50, 1392-1396.

[14] Murti, Y., Goswam, A. and Mishra, P. (2013) Synthesis and Antioxidant Activity of Some Chalcones and Flavanoids. Inter J Pharm Tech Res, 5, 811-818.

[15] Prakash, O., Kumar, R. and Prakash, V. (2008) Synthesis and Antifungal Activity of Some New 3-Hydroxy-2-(1-Phenyl-3-Aryl-4-Pyrazolyl) Chromones. European Journal of Medicinal Chemistry, 43, 435-440. https://doi.org/10.1016/j.ejmech.2007.04.004

[16] Ghawalkar, A.R., Nagargoje, D.R. and Shingare, M.S. (2007) Synthesis of Some Gallic Acid Incorporated Flavones. Indian Journal of Heterocyclic Chemistry, 17, 185-186.

[17] Lembege, M.V., Moreau, S. and Larrouture, S. (2008) Synthesis and Antiproliferative Activity of Aryl- and Heteroaryl-Hydrazones Derived from Xanthone Carbaldehydes. European Journal of Medicinal Chemistry, 43, 1336-1343. https://doi.org/10.1016/j.ejmech.2007.09.003

[18] Binaschi, M., Zunino, F. and Capranico, G. (1995) Mechanism of Action of DNA Topoisomerase Inhibitors. Stem Cells, 13, 369-379. https://doi.org/10.1002/stem.5530130408

[19] Rath, P.C. and Aggarwal, B.B. (1999) TNF Induced Signaling in Apoptosis. Journal of Clinical Immunology, 19, 350-364. https://doi.org/10.1023/A:1020546615229

[20] Varfolomeev, E.E., et al. (1998) Targeted Disruption of the Mouse Caspase 8 Gene Ablates Cell Death Induction by the TNF Receptors, Fas/Apo1, and DR3 and Is Lethal Prenatally. Immunity, 9, 267-276. https://doi.org/10.1016/S1074-7613(00)80609-3

[21] Kamal, A., Kumar, G.B., Nayak, V.L., Reddy, V.S., et al. (2015) Design, Synthesis and Biological Evaluation of Imidazopyridine/Imidazopyrimidine-Benzimidazole Conjugates as Potential Anticancer Agents. Med Chem Comm, 6, 606-612.

https://doi.org/10.1039/C4MD00400K 
Supporting Information

STRUCTURAL INFORMATION OF COMPOUNDS

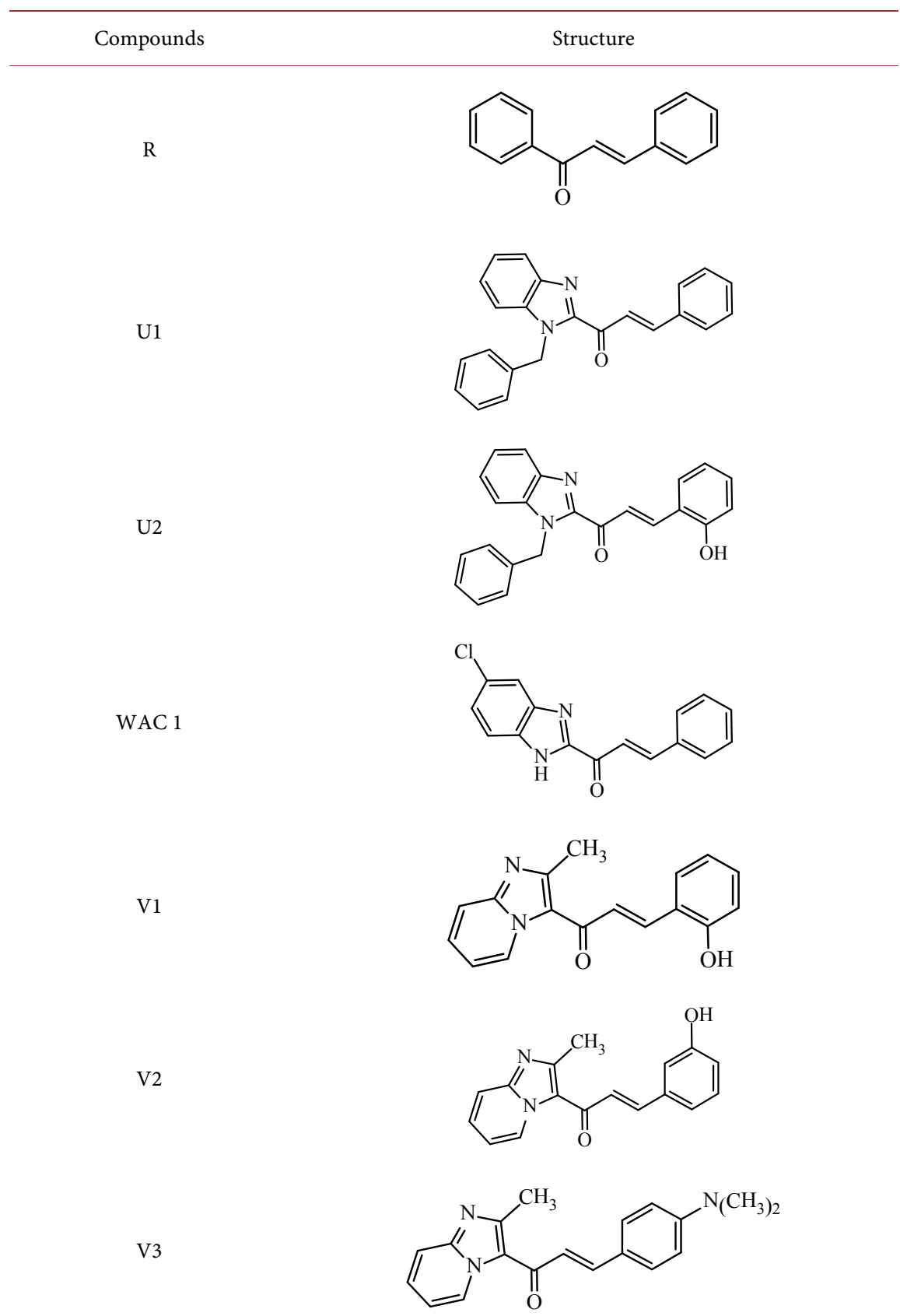

\section{SYNTHESIS INFORMATION OF THESE COMPOUNDS}

Synthesis of Imidazopyridinyl-chalcone [8]<smiles>CC(=O)c1c(C)nc2ccccn12</smiles><smiles>[R]c1cccc(C=O)c1</smiles><smiles>Cc1nc2ccccn2c1C(=O)/C=C/c1ccccc1</smiles> 


\section{Synthesis of benzimidazolyl-chalcone [9]}

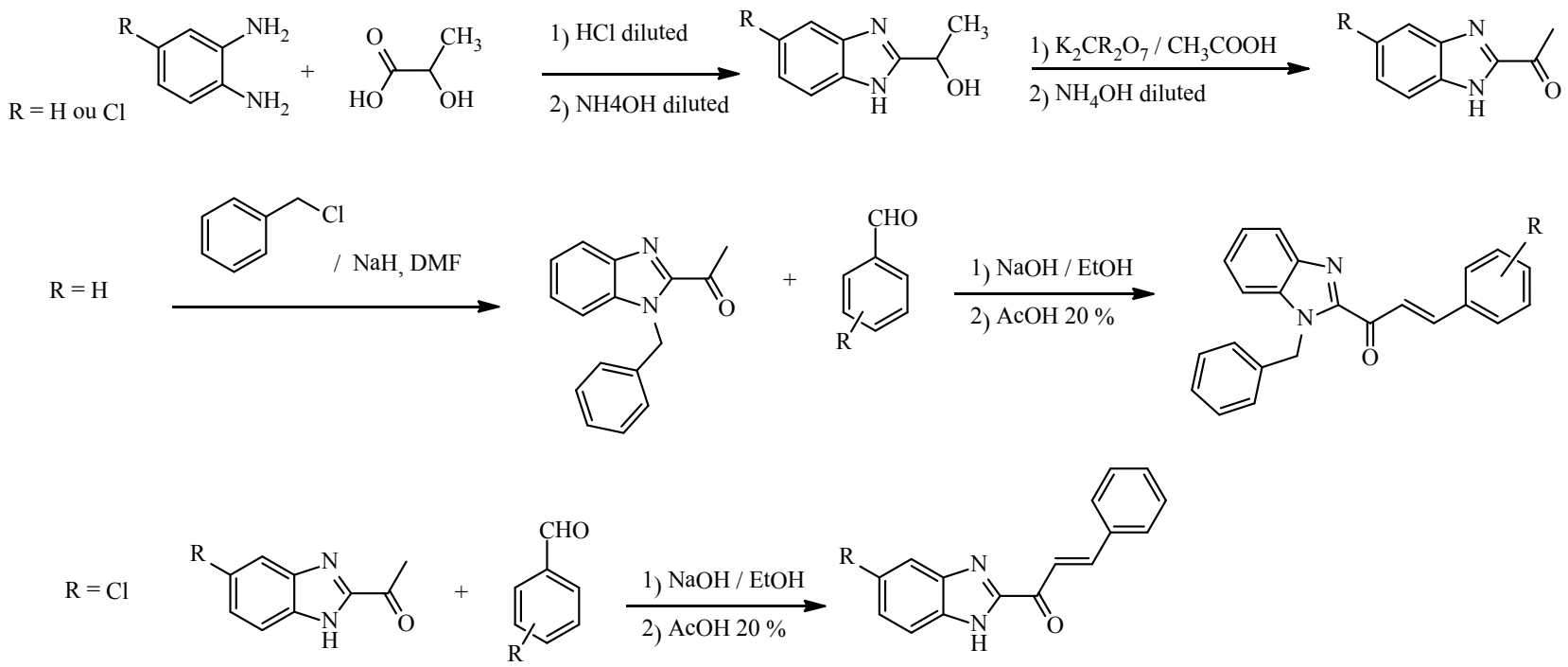

\section{References}

[8] Sissouma, D., Ouattara, M., Koné, M.W., Menan, H.E., Adjou, A. and Ouattara, L. (2011) Synthesis and in Vitro Nematicidal Activity of New Chalcones Vectorised by Imidazopyridine. African Journal of Pharmacy and Pharmacology, 5, 2086-2093. https://doi.org/10.5897/AJPP11.550

[9] Ouattara, M., Sissouma, D., Yavo, W. and Kone, M.W. (2015) Synthèse et criblage antiplasmodial de quelques benzimidazolyl-chalcones. International Journal of Biological and Chemical Sciences, 9, 1697-1710. https://doi.org/10.4314/ijbcs.v9i3.48 